\title{
Outcome of pregnancy in women with valve
} prostheses

\author{
Eftihia Sbarouni, Celia M Oakley
}

\begin{abstract}
Objective-To study the outcome of pregnancy in women with artificial heart valves treated in major European centres, and to compare the safety and efficacy of different anticoagulant regimens and of mechanical and bioprosthetic valves.

Design-Retrospective study.

Method-The information was obtained by questionnaire sent to all major cardiac centres in Europe sending one cardiologist from each centre a covering letter suggesting that the questionnaire be handed on where appropriate to the most relevant colleague.
\end{abstract}

Results-214 pregnancies were reported in 182 women; 151 pregnancies in 133 women with mechanical valves, and 63 pregnancies in 45 women with bioprostheses. Most women were in New York Heart Association class I or II and in sinus rhythm. 150 women with mechanical valves and $11(17 \%)$ with bioprotheses received anticoagulants during pregnancy. One patient with an aortic valve prosthesis refused to take anticoagulants. Including the spontaneous abortions reported as well as the therapeutic abortions $83 \%$ of the pregnancies in women with bioprostheses and $73 \%$ in those with mechanical valves resulted in a healthy baby, full term or premature, who did well (NS). The incidence of stillbirths (3\% and $6 \%$ ) and of reported spontaneous abortions (10\% and $12 \%)$ did not differ between the two groups. If the spontaneous abortions are excluded (because they are unlikely to have been fully reported), the success rate was $91 \%$ for women with bioprosthetic valves and $84 \%$ for women with mechanical valves (NS). $114(53 \%)$ of the women had taken warfarin for some part of the pregnancy (46 $(40 \%)$ of these during the first trimester) but there were no embryopathies. There were 13 valve thromboses (four fatal), eight embolic events (two fatal), and seven bleeds in women with mechanical valves. Most of these complications occurred with heparin but fatal aortic valve thrombosis occurred in the one woman who refused anticoagulant treatment out of the 151 women with mechanical valves. There were no mater- nal deaths in the bioprosthesis group but in $17 / 49(35 \%)$ of these valves functional deterioration led to urgent replacement during pregnancy (two) or soon after. Conclusions-The outcome of pregnancy was similar for women with mechanical valves or bioprostheses. Warfarin treatment was safe and effective and was not associated with embryopathy. Heparin treatment was associated with more thromboembolic complications and more bleeding complications. Bioprostheses deteriorate rapidly during pregnancy.

(Br Heart F 1994;71:196-201)

There is still no consensus on the most suitable heart valve replacement for women of childbearing age. Mechanical valves carry a risk of thromboembolism and the need for anticoagulation whereas bioprostheses have a lower thromboembolic risk but are not as durable, particularly in the young. There is controversy about the safest anticoagulant regimen during pregnancy. Early reports of pregnancy in women with mechanical valves were usually of anecdotal cases: they were inspired by disaster rather than by success. Most of these reports came from the United States where overanticoagulation was the rule because of the use of thromboplastins of low responsiveness. ${ }^{1}$ There is still no universal adoption of the International Normalised Ratio (INR) in the United States though lower prothrombin ratios, which are equivalent to our recommended INRs, are advocated now. Previously recommended prothrombin ratios in the United States were equivalent to INRs of up to nine. Unsafe American practice built on American results with an outmoded system has, unfortunately, adversely influenced practice outside the United States. Later reports of series of pregnancies in women with mechanical valves came from the developing world where it was difficult to achieve optimal anticoagulant supervision. Pregnancy is a hypercoagulable state $^{2}$ and the risk of thromboembolic complications is higher during pregnancy than at other times. ${ }^{3}$ Anticoagulation is essential for women with a mechanical valve and for those with a bioprosthesis who are in atrial fibrillation or have a history of thromboembolism. 
Antiplatelet agents do not offer protection. ${ }^{4}$ Heparin carries a high risk of fetal loss from retroplacental haemorrhage as well as maternal bleeding events, the various regimens are non standardised, hard to control, and heparin's efficacy in preventing arterial thromboembolism is not established. ${ }^{5}$ Coumarin derivatives are alleged to increase fetal wastage by bringing a risk of warfarin embryopathy during the first trimester as well as a continuing risk of central nervous system damage throughout pregnancy. ${ }^{4}$

We report the results of a survey obtained through questionnaires sent to cardiologists in the United Kingdom and Europe in which they were asked about their recommended practice as well as for details of cases from their experience. This survey was sponsored by the Working Group on Valve Disease of the European Society of Cardiology to clarify the outcome in young women whose pregnancies and anticoagulant treatment would be well supervised at major western European cardiac centres.

\section{Patients and methods}

\section{QUESTIONNAIRE}

The first part of the questionnaire asked the recipient cardiologist which type of replacement heart valve was recommended for young women at their centre and what anticoagulant regimen was advised during pregnancy. The second part sought case reports of all women with artificial valves managed during pregnancy in their centre.

Though three fifths of the cardiologists replied that they would choose a bioprosthesis for a young woman, $70 \%$ of the reported pregnancies occurred in women with mechanical valves. The preferred policy, as described, seemed to differ from practice.

\section{POPULATION}

Two hundred and fourteen pregnancies in 182 women aged 14-48 (mean 30 (SD 6) years) were reported to us. One hundred and fifty one pregnancies occurred in 133 women with mechanical valves and 63 pregnancies in 49 women with bioprostheses.

Most women were haemodynamically stable (New York Heart Association (NYHA) class I or II) and in sinus rhythm but 11 women were in NYHA class III or IV at the onset of pregnancy and therefore at higher risk on haemodynamic grounds and less likely to carry a pregnancy safely to term. More than half of the women studied (115) had a mitral prosthesis, 43 had an aortic prosthesis,

Table 1 Clinical characteristics of 182 women

\begin{tabular}{llllll}
\hline Functional NYHA class (n) & I (96) & II (68) & III (9) & IV (2) & U (7) \\
Rhythm (n) & SR (144) & AF(34) & P (2) & U (2) & \\
Position of prosthesis (n) & M (115) & A (43) & M + A (19) & U (5) & \\
Type of mechanical prosthesis(n) & BS(39) & SE (30) & SJ (18) & O (12) & U (34) \\
Type of bioprosthesis (n) & CE (21) & H (19) & IS (8) & O (5) & U (6) \\
\hline
\end{tabular}

A, sortic; AF, atrial fibrillation; BS, Björk-Shiley; CE, Carpentier-Edwards; H, Hancock IS, Ionescu-Shiley; M, mitral; $M+A$, mitral and aortic; $O$, others; $P$, paced rhythm SE, Starr-Edwards; SJ, St Jude; SR, sinus rhythm; U, unknown. and 19 had mitral and aortic prostheses. Sixty nine had either Björk-Shiley or Starr-Edwards valves (table 1). The interval between valve replacement and the first pregnancy was $0 \cdot 5-14$ (mean 4.45 (SD 3.22) years).

Seventeen women with mechanical valves and 10 with bioprostheses had more than one pregnancy (23 women had had two pregnancies, three women had had three, and one had had four pregnancies) all of which were included in this study. Twenty with mechanical valves and seven with bioprostheses had also had more than one (two pregnancies in 25 and three pregnancies in two) details of which were not made available.

Thirteen of the pregnancies reported occurred before 1975, 90 between 1975 and 1985, and 111 after 1985.

\section{ANTICOAGULATION}

Eleven (17\%) of the 49 women with bioprostheses were taking anticoagulants because of atrial fibrillation. Three were receiving subcutaneous heparin throughout, six warfarin throughout, and two subcutaneous heparin for the first trimester and warfarin thereafter. Warfarin was changed to intravenous heparin 2-4 weeks before labour except when births were premature.

Anticoagulants were taken during 150 out of the 151 pregnancies in women with mechanical valves. Thirty four were receiving subcutaneous heparin throughout pregnancy, 50 warfarin throughout pregnancy, and 66 subcutaneous heparin for the first trimester and warfarin thereafter. Again warfarin was replaced by intravenous heparin 2-4 weeks before labour except when births were premature.

\section{STATISTICAL ANALYSIS}

Differences in discrete variables between patient groups were compared by $\chi^{2}$ test. A $p$ value of $<0.05$ was considered significant.

\section{Results}

FETAL OUTCOME

Ten women with mechanical valves had abortions at their request and are excluded from further analysis. One woman with a mechanical aortic prosthesis refused anticoagulant treatment and died from valve thrombosis. She too was excluded leaving 140 pregnancies for analysis in women with mechanical valves.

Though the incidence of reported spontaneous abortions reported was similar in the groups with bioprosthetic and mechanical valves, these abortions were excluded from the calculations. The main reason for this was that they were unlikely to be as accurate in this retrospective survey as the figures for prematurity, fetal abnormality, stillbirth, and neonatal and maternal death. Prematurity was defined as birth after less than 36 weeks' gestation. It was not possible to obtain information about the extent of prematurity in individual cases or about birth weights. 
Table 2 Outcome of pregnancy of women with bioprostheses according to whether or not they were taking an anticoagulant

\begin{tabular}{lll}
\hline & $\begin{array}{l}\text { Off anticoagulant } \\
(\text { total } n=49)(n(\%))\end{array}$ & $\begin{array}{l}\text { On anticoagulant } \\
(\text { total } n=8)(n(\%))\end{array}$ \\
\hline Healthy babies: & $44(91)$ & $8(100)$ \\
Full term & $41(84)$ & $7(87 \cdot 5)$ \\
Premature & $3(7)$ & $1(12 \cdot 5)$ \\
Stillbirths & $2(4)$ & 0 \\
Neonatal deaths & 0 & 0 \\
Therapeutic abortions & $3(6)$ & 0 \\
\hline
\end{tabular}

\section{Bioprostheses}

Excluding the six spontaneous abortions, the 57 pregnancies in the bioprosthesis group produced 52 healthy babies (91\%), 48 full term and four premature. There were two stillbirths and three therapeutic abortions (table 2). Two of the therapeutic abortions were related to valve complications and one was because of heart failure class III. There were no neonatal deaths or fetal abnormalities. Table 2 shows the outcome separately for the pregnancies of women taking and not taking anticoagulants.

\section{Mechanical valves}

Seventeen spontaneous abortions were reported in the mechanical valve group. Excluding these, 124 pregnancies resulted in 105 healthy babies, 75 full term and 30 premature $(85 \%)$. There were nine stillbirths and three neonatal deaths, two due to extreme prematurity and one to cerebral haemorrhage. Only one stillbirth occurred in the group taking heparin followed by warfarin (66 mothers) but there were four in the group taking warfarin throughout (only 36 women) and also four in the group on heparin throughout (only 30 women). The last four stillbirths were associated with fatal valve thrombosis. The four stillbirths in the group receiving warfarin were associated with prematurity but not with detected fetal abnormality. Two of the neonatal deaths were babies of women who had been treated with

Table 3 Outcome of pregnancy in women with mechanical valves

\begin{tabular}{lc}
\hline Outcome & No (\%) \\
\hline Pregnancies & 124 \\
Healthy babies: & $105(85)$ \\
Full term & $75(60)$ \\
Premature & $30(25)$ \\
Stillbirths & $9(7)$ \\
Neonatal deaths & $3(2)$ \\
CNS abnormalities & 1 \\
Embryopathies & 0 \\
Therapeutic abortions & $3(2)$ \\
Not delivered (maternal death) & 2 \\
Ectopic pregnancy & 1 \\
\hline
\end{tabular}

Table 4 Outcome of pregnancy: comparison between mechanical valves and bioprostheses

\begin{tabular}{lll} 
& $\begin{array}{l}\text { Bioprostheses } \\
(\text { total } n=57)(n(\%))\end{array}$ & $\begin{array}{l}\text { Mechanical } \\
(\text { total } n=124)(n(\%))\end{array}$ \\
\hline Healthy babies: & $52(91)$ & $105(85)$ \\
Full term & $48(84)$ & $75(60)$ \\
Premature & $4(7)^{\star}$ & $30(25)^{\star}$ \\
Stillbirths & $2(4)$ & $9(7)$ \\
Therapeutic abortions & $3(5)$ & $3(2)$ \\
\hline
\end{tabular}

warfarin throughout pregnancy; one had been treated with heparin for the first trimester and warfarin thereafter. Two of the three therapeutic abortions were performed because of heart failure NYHA class III and IV. There were no embryopathies. One central nervous system abnormality (mental retardation) was recorded, the mother having been treated with intravenous heparin in the first trimester and warfarin thereafter. One baby with congenital adrenal hyperplasia (a recessively inherited condition unrelated to warfarin treatment) has done well. Two babies were not delivered owing to maternal death and there was also one ectopic pregnancy (table 3).

The numbers of healthy babies were similar in the two groups but the incidence of prematurity was significantly lower $(p<0.05)$ in the bioprosthesis group (table 4).

Table 5 shows the outcome for the babies according to the different anticoagulant regimens. There was no difference in outcome between patients taking no anticoagulant and patients taking heparin for the first trimester and warfarin thereafter, except for a lower incidence of prematurity $(p<0.05)$. Nor was there any difference in the outcome between patients taking warfarin throughout and patients on heparin throughout. Women taking heparin followed by warfarin were more likely to have a healthy baby than women taking heparin throughout pregnancy $(p<0.05)$. The incidence of stillbirths was also lower in women taking heparin followed by warfarin than in either women taking warfarin throughout or heparin throughout $(p<0.05)$.

The outcome for women with multiple pregnancies or multiple valves was comparable with the overall result.

\section{MATERNAL OUTCOME}

\section{Bioprostheses}

There were no maternal deaths in the bioprosthesis group despite two emergency valve replacements and no thromboembolic or bleeding complications in any of the pregnancies, including those in the 11 women taking anticoagulants.

Seventeen (35\%) of the 49 valves deteriorated remarkably in function either during pregnancy or shortly after it. Fifteen of these $(31 \%)$ have already been replaced, two as emergencies during pregnancy and 13 electively after it. The remaining two await replacement. The valve was CarpentierEdwards in seven, Hancock in five, IonescuShiley in two, and other types in three.

\section{Mechanical valves}

There were six maternal deaths in the mechanical valve group, four caused by valve thrombosis, one by cerebral embolism, and one by pulmonary oedema (NYHA I, no thrombus on the valve at necropsy). Four women were receiving warfarin, one heparin, and one was not taking anticoagulants. Nine of the 13 valve thromboses were not fatal. Five were treated by emergency valve replacement and four were managed medically with 
Table 5 Outcome of pregnancy according to different anticoagulant regimens

\begin{tabular}{lllll}
\hline & $\begin{array}{l}\text { No anticoagulant } \\
(49 B) \\
(n(\%))\end{array}$ & $\begin{array}{l}\text { Heparin for first trimester then warfarin } \\
(64 M+2 B) \\
(n(\%))\end{array}$ & $\begin{array}{l}\text { Warfarin throughout } \\
(31 M+5 B) \\
(n(\%))\end{array}$ & $\begin{array}{l}\text { Heparin throughout } \\
(29 M+1 B) \\
(n(\%))\end{array}$ \\
\hline Healthy babies: & $44(91)$ & $61(92) \dagger$ & $30(83)$ & $22(73) \dagger$ \\
Full term & $41(84)$ & $42(64)$ & $23(64)$ & $17(57)$ \\
Premature & $3(6)^{\star}$ & $19(29)^{\star}$ & $4(19)$ & $5(17)$ \\
Stillbirths & $2(4)$ & $1(1.5) \ddagger$ & $2(3)$ & $4(13) \ddagger$ \\
Neonatal deaths & 0 & $1(1.5)$ & $1(3)$ & 0 \\
Therapeutic abortion & $3(6)$ & 0 & $2(7)$ & \\
\hline
\end{tabular}

$\star, t, \ddagger ; p<0.05$. B, bioprostheses; $M$, mechanical valves.

thrombolytic agents (two with streptokinase and two with alteplase). Ten of the 13 women with thrombosed valves were taking heparin, two were taking warfarin, and one was not taking anticoagulants (heparin $v$ warfarin $\mathrm{p}<0.05)$. Twelve of the 13 thrombosed valves were mitral and only one was aortic (no anticoagulant). Five of the mitral prostheses were Björk-Shiley, four were StarrEdwards, one was a St Jude, and there were two others.

There were eight major embolic events, two fatal (one was associated with valve thrombosis) and six without permanent sequelae. Five women were taking heparin and three warfarin $(p<0 \cdot 05)$. Table 6 shows these thromboembolic complications.

There were seven major bleeding complications needing more than two units of transfused blood, five during pregnancy and two postpartum requiring hysterectomy. Five women were treated with heparin and two with warfarin $(\mathrm{p}<0.05)$.

Of the 34 pregnancies in 29 women with mechanical valves treated with heparin throughout, eight $(24 \%)$ were complicated by valve thrombosis, four (12\%) by embolic events and four (12\%) by major bleeding, giving a major complication rate of $48 \%$. There was also one case of severe osteopenia in a woman treated with heparin throughout pregnancy but no thrombocytopenia was reported.

\section{Discussion}

Some regard bioprostheses as the best valves for women with valve disease who wish to have children. This is because treatment with anticoagulants can usually be avoided. Though this was the view of most of the respondents to the questionnaire many of them also indicated that they had no personal experience of pregnancy in a woman with an

Table 6 Valve thromboses and embolism during pregnancy

\begin{tabular}{lll}
\hline & $N o$ & Valve \\
\hline Thrombosed valves: & 13 & 12 mitral, 1 aortic \\
$\quad$ Fatal & 4 & \\
Anticoagulant: & 1 (refused) & Aortic \\
$\quad$ None & 10 & All mitral \\
$\quad$ Heparin & 2 & \\
$\quad$ Warfarin & 8 & \\
Major embolic events: & 2 (including 1 with thrombosed valve) & \\
Fatal & 5 & All mitral \\
Anticoagulant: & 3 & \\
$\quad$ Heparin & & \\
$\quad$ Warfarin & &
\end{tabular}

artificial valve of any sort. Most of the women in this study with a bioprosthesis went through pregnancy successfully without anticoagulant treatment. The fetal outcome was excellent and our data for this group do not differ from the normal population. ${ }^{6}$ This accords with previous reports. ${ }^{37-9}$ The outcome was only slightly less favourable for the babies of mothers with mechanical valves. The difference did not reach statistical significance, except for prematurity.

This slight advantage for the babies of mothers with bioprostheses has to be set against the expectation of accelerated valve failure and the need for early reoperation with its mortality and morbidity at a time when both the children and their mothers are still young. More than a third of the young women with a bioprothesis in this study developed primary valve dysfunction and had repeat replacement. Similarly, almost $60 \%$ of the bioprotheses failed in the series of Bortolloti et al, ${ }^{10}$ and $13 \%$ had to be replaced in that of Salazar et al 7-12 months after delivery. ${ }^{4}$ In another group of 87 women with bioprotheses the incidence of structural valve deterioration and reoperation was $47.1 \%$ and $59 \%$ for women going through pregnancies $v$ $14.3 \%$ and $19 \%$ (both $p<0.05$ ) for those who did not. The mean interval from operation to reoperation was only $72 \cdot 1$ months. ${ }^{11}$ Premature valve failure is a well recognised complication of bioprostheses, particularly in young people. It seems that pregnancy can further accelerate this process. Increased calcium turnover is probably the reason: this is blamed for poor durability of bioprostheses in children and calcium turnover will be even higher in pregnancy. Therefore pregnancy is an independent risk factor for very rapid bioprosthetic failure. Because reoperation is technically more difficult and carries an increased risk this grave disadvantage of bioprostheses in young women should not be lightly dismissed. The overall risk of single valve re-replacement obtained from the United Kingdom Cardiac Surgery Registry for 1991 and 1992 was $11.5 \%$ but for patients under 50 years the risk is probably somewhat lower. There is a tendency for the mortality and morbidity of valve re-replacement to be underestimated. Bioprostheses are now only advised for patients whose life expectancy is shorter than that of the valve (unless there are uncorrectable bleeding hazards). Why should young women be singled out for obligatory reoperation with its attendant risks? 
There were no embryopathies in the group of 36 women on warfarin throughout pregnancy. Likewise, Chen et al, ${ }^{12}$ Ben Ismail et $a l^{13}$ and Pavankumar et $a l^{14}$ did not recognise any embryopathies in their 22, 53, and 47 patients who were taking oral anticoagulants in the first trimester. The incidence of embryopathy in other studies varies from $4 \%$ to $7 \cdot 9 \%,{ }^{15-17}$ and the risk of malformed neonates has been estimated to be less than $5 \% .{ }^{18} 19$ Only one study reports a much higher incidence of up to $29.6 \%$ but the abnormalities in these babies were identified by clinical geneticists. ${ }^{17}$ Over anticoagulation was likely to increase fetal bleeding complications including haemorrhage into developing cartilaginous bone and embryopathy. ${ }^{20}$

In our study the fetal outcome did not differ in the groups given warfarin and heparin throughout pregnancy, the reported abortion rate being $22 \%$ for each and the stillbirths $9 \%$ and $11 \%$ respectively. The incidence of spontaneous abortion reported in women taking oral anticoagulants throughout pregnancy varies widely, values of $4 \cdot 2 \%, 13 \quad 18 \%,,^{14}$ $28 \cdot 1 \%,{ }^{3} 35 \%,{ }^{21} 44 \%,{ }^{22}$ to almost $50 \%{ }^{23}$ being quoted. The discrepancy is probably largely caused by incomplete reporting of abortion, the incidence of which is estimated at between $15 \%$ and $25 \%$ in normal healthy women, but is likely also to be affected by intensity of anticoagulation. There are only a few reports of outcome of pregnancy in women taking heparin throughout, two successful pregnancies in one study, ${ }^{24}$ three out of five abortions in another. ${ }^{12}$ Ayan et al described a $9 \cdot 1 \%$ incidence of abortions in women taking heparin, the total foetal wastage being statistically no different from their coumarin group..$^{25}$ Fetal wastage is due to placental detachment due to haemorrhage or to valve thrombosis. The fetal outcome was slightly better in women taking the combination of heparin in the first trimester and warfarin thereafter compared with those taking either warfarin or heparin throughout and this scheme is widely recommended. This is because warfarin embryopathy is throught to occur between the sixth and the ninth week. None the less, long-term heparin is not without complications ${ }^{26}$ and it exposes women to the greater hazards of heparin during that time. Larrea et al reported a lower incidence of fetal complications in women receiving intravenous heparin in the first trimester and warfarin thereafter than in those taking warfarin throughout but at the expense of increased maternal mortality. ${ }^{16}$ Lee et al reported a $50 \%$ incidence of abortions with subcutaneous heparin adjusted to an activated partial prothrombin time of $1 \cdot 5 .{ }^{27}$ In the study of Hurbe-Allessio et al the incidence of abortions in women receiving heparin in the first trimester was the same as in the warfarin group. ${ }^{17}$ Embryopathy is rare when the dose of warfarin is well controlled and the increased maternal hazard from heparin is surely not justifiable. Cotrufo and colleagues suggested that fetal risk is related to maternal dose of coumarin anticoagulant rather than to the INR achieved. They selected 20 women whose warfarin requirement was less than $5 \mathrm{mg}$ per day for anticoagulation with warfarin throughout pregnancy. There were no abortions, stillbirths, embryopathies, or other complications. ${ }^{28}$

Maternal complications were higher in the women with a mechanical valve than in women with a bioprosthesis but they were nearly all related to heparin treatment. There were 13 valve thromboses of which four were fatal, eight embolic events of which two were fatal, and seven bleeds. Most of these complications occurred in women receiving heparin. This is in agreement with previous studies. Wang et al described five thromboembolic events in 10 patients with 14 pregnancies when heparin (5000 IU subcutaneously twice daily) was substituted for warfarin in the first trimester. ${ }^{29}$ In the series of Salazar et al there was an $8.3 \%$ incidence of cerebral embolism when heparin was used in the first trimester compared with $2.3 \%$ in women continuing to receive warfarin during this period. ${ }^{4}$ In the study of Hurbe-Allessio et al all three of the women who developed valve thrombosis were receiving subcutaneous heparin and two of the three died. ${ }^{17}$ The same is true for the series of Larrea et al with three valve thromboses, one fatal (all of whom were receiving intravenous heparin) ${ }^{16}$ and in the series of Vitalli et al with two valve thromboses, both fatal (both receiving subcutaneous heparin). ${ }^{23}$ In Cotrufo's small series elective caesarean section was performed at 38 weeks after warfarin had been stopped for 48 hours. Only one out of 20 patients went into spontaneous labour at 36 weeks and all the babies and mothers did well. ${ }^{28}$

The women in this study, most of them haemodynamically stable before pregnancy, tolerated the circulatory overload of pregnancy well. One patient had fatal pulmonary oedema that was not caused by valve thrombosis.

\section{RECOMMENDATIONS}

Because of accelerated valve degeneration and the need for early reoperation bioprostheses should not be recommended to young women who intend to become pregnant. Pregnancy does not - carry increased risk for fit women with mechanical valves who comply with oral anticoagulant treatment, and the outcome is likely to be successful particularly if the dose requirement is low.

Heparin is neither effective nor safe for long-term use in pregnancy bringing an increased risk of both thromboembolism and bleeding with hazard to mother and fetus. It is recommended only for intravenous use in hospital in the last two weeks before delivery when these complications can be detected and averted because both mother and fetus are under observation. This is not true for low molecular weight heparin given at home when fluctuations in anticoagulant control go unnoticed as do early signs of valve thrombosis or fetal distress. Elective caesarean section at 38 weeks is an alternative strategy that 
avoids the need for conversion to heparin for the last two weeks.

\section{STUDY LIMITATIONS}

In this a long retrospective study more than half of the pregnancies reported occurred after 1985. The study population is not homogeneous, though most women were young, haemodynamically stable, and had rheumatic heart disease. An important limitation is that we do not have detailed information on the level of anticoagulation on the dose throughout pregnancy. We knew from the questionnaire what was aimed at and considered optimal both for warfarin and heparin but it would have been very time consuming and probably impossible for our colleagues to have obtained all these figures retrospectively. The target for the INR was generally stated to be between 3.0 and 4.0 . The target partial thromboplastin time was twice the control value. We do not know whether these targets were reached or the values at the time that complications developed. Anticoagulant control should now be prosthesis specific with lower targets set for second generation mechanical valves and an INR of between $2 \cdot 0$ and 3.0 in pregnancy. ${ }^{30}$

Finally, the cases analysed represent the experience only of those cardiologists who took the trouble to provide details of their patients. The data are to that extent selective but otherwise unbiased.

We thank all of our colleagues who responded, particularly Dr Hanania who accumulated the French data, and Professo Krzeminska-Pakula for reporting many cases from Poland We thank Professor Ken Taylor, for access to the United Kingdom Valve Registry held at Hammersmith Hospital.

1 Hirsh J. Is the dose of warfarin prescribed by American physicians unnecessarily high? Arch Intern Med 1987; 147:769-71.

2 Shaper AG. The hypercoagulable States. Ann Intern Med 1985;102:814-28

3 Limet R, Grondin CM. Cardiac valve prostheses, anticoagulation and pregnancy. Ann Thorac Surg 1977;23: 337-41.

4 Salazar E, Zajarias A, Gutiarraz N, Iturbe I. The problem of cardiac valve prostheses: anticoagulants and pregnancy. Circulation 1984;70(suppl 1):169-77.

5 Ginsberg JS, Hirsch J. Anticoagulants during pregnancy. Ann Rev Med 1989;40:79-86.

6 Ginsberg JS, Kowalchuk G, Hirsch J, Brill-Edwards P, Burrows R. Heparin therapy during pregnancy. Ann Intern Med 1989;149:2233-6.

7 Oakley C, Doherty P. Pregnancy in patients after valve replacement. Br Heart $\mathcal{F}$ 1976;38:1140-8.

8 Denbow CE, Matadial L, Sivapragasam S, Spencer H. Pregnancy in patients after homograft cardiac valve replacement. Chest 1983;83:540-1.

9 Nunez L, Larrea JL, Aguado MG, Reque JA, Matorras R, Minguez JA. Pregnancy in 20 patients with bioprosthetic valve replacement. Chest 1983;84:26-8.

10 Bortolloti U, Milano A, Mazzucco A, Valgre C, Russo R, Valente $M$, et al. Pregnancy in patients with a porcine valve prosthesis. Am f Cardiol 1982;50:1051-4.

11 Badduke ER, Jamieson RE, Miyashima RT, Munro AI, Gerein AN, MacNab J, Tyers GFO. Pregnancy and childbearing in a population with biologic valvular proschildbearing in a population with biologic valvular
theses. $\mathcal{F}$ Thorac Cardiovasc Surg 1991;102:179-86.
12 Chen WWC, Chan CS, Lee PK, Wang RYC, Wong VCW. Pregnancy in patients with prosthetic heart valves: an experience with 45 pregnancies. $Q f \mathrm{Med}$ 1982;51:358-65.

13 Ben Ismail $M$, Abid F, Trabeisi S, Tarktak M, Fekih $M$. Cardiac valve prostheses, anticoagulation and pregnancy. Br Heart $\mathcal{F} 1986 ; 55: 101-5$.

14 Pavankumar P, Venugopal P, Kaul U, Lyer KS, Sas B, Sampathkumar A, et al. Pregnancy in patients with prosthetic cardiac valves-A 10 year experience. Scand $f$ prosthetic cardiac valves-A 10 year exp

15 Sareli P, England MJ, Berk MR, Marcus RH, Epstein M, Driscoll J, et al. Maternal and fetal sequelae of anticoagulation during pregnancy in patients with mechanical heart valve prostheses. Am $f$ Cardiol 1989; 63:1462-5.

16 Larrea JL, Nunez L, Reque JE, Gil Aguado M, Matarros $R$, Mingues JA. Pregnancy and mechanical valve prostheses is a high risk situation for the mother and the fetus. Ann Thorac Surg 1983;36:459-63.

17 Iturbe-Alessio I, Delcarmen Fonseca M, Mutchinik D, Mutchinik O, Santos MA, Zajarias A, Salazar E. Risks of anticoagulant therapy in pregnancy in women with artificial heart valves. N Engl $₹$ Med 1986;27:1390-3.

18 de Swiet M. Anticoagulants. BMF 1987;294:428-30.

Chong MKB, Harvey D, de Swiet MD. Follow-up study of children whose mothers were treated with warfarin

20 Stevenson RE, Burton M, Ferlauto GR, Taylor HA. Hazards of oral anticoagulation during pregnancy. HAMA 1980;243:1549-51.

21 Ibarra-Perez C, Aravalo-Toledo N, Alvarez-de la Cadena O, Noriega-Guera L. The course of pregnancy in

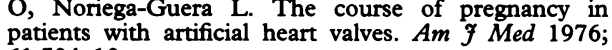
patients with

22 Lutz DJ, Nollar KL, Spittal JA, Danielson GK, Fish CR. Pregnancy and the complications following cardiac valve prostheses. Am $\mathcal{F}$ Obstet Gynaecol 1978;131:460-8.

23 Vitali E, Donatelli F, Quaini E, Gropelli G, Pellegrini A. Pregnancy in patients with mechanical prosthetic valves: our experience regarding 98 pregnancies in 57 patients. $\mathcal{f}$ Cardiovasc Surg 1986;27:221-7.

24 Guidozzi F. Pregnancy in patients with prosthetic cardiac values. $S$ Afr Med $\mathcal{F} 1984 ; 65: 961-3$.

25 Ayan A, Yapar EG, Yuce K, Kinciki HA, Nazli N, Ozmen F. Pregnancy and its complications after cardiac valve replacement. Int $f$ Gynecol Obstet 1991;35:117-22.

26 Howell R, Fidler J, Letsky E, De Swiet M. The risks of antenatal subcutaneous prophylaxis: a controlled trial. Br f Obstet Gynaecol 1983;90:1124-8.

27 Lee PK, Wang RYC, Cho JSF, Cheung KL, Wong VCW, Chan TK. Combined use of warfarin and adjusted heparin during pregnancy in patients with artificial heparin during pregnancy in patient
valves. $₹ \mathrm{Am}$ Coll Cardiol 1986;8:221-4.

28 Wang RYC, Lee PK, Chow JF, Chen WWC. Efficacy of low dose subcutaneously administered heparin in treatment of pregnant women with artificial heart valves. Med F A ust 1983;2:126-7.

28 Cotrufo M, de Luca TSL, Calabro R, Mastrogiovanni G, Lama D. Coumarin Anticoagulation during pregnancy in patients with mechanical valve prostheses. Eur $\mathcal{F}$ Cardiothorac Surg 1991;5:300-5.

29 Wang RYC, Lee PK, Chow JF, Chen WWC. Efficacy of low dose subcutaneously administered heparin in treatment of pregnant women with artificial heart valves. Med ₹ A ust 1983;2:126-7.

30 Ad Hoc Committee of the Working Group on Valvular Heart Disease: Guidelines for Prevention of thromboembolic events in valvular heart disease. Official document of the European Society of Cardiology. f Heart Valve Dis 1993;2:398-410.

\section{Addendum}

Since submission of this paper a further case of valve thrombosis has been notified to us. This was in a 25 year old woman with a HallKaster mechanical mitral prosthesis $(29 \mathrm{~mm})$ which thrombosed at 34 weeks' gestation while she was being treated with subcutaneous heparin. Emergency mitral valve re-replacement was carried out after delivery of the baby by caesarean section. Both mother and child survived. 